\title{
Monitoring and Prediction of Traffic Noise in Large Urban Areas
}

\author{
Giovanni Zambon ${ }^{1}$, Hector Eduardo Roman ${ }^{2}$, Maura Smiraglia ${ }^{1}$ and Roberto Benocci ${ }^{1, *}$ \\ 1 Department of Earth and Environmental Sciences (DISAT), University of Milano-Bicocca, Piazza della \\ Scienza 1, 20126 Milano, Italy; giovanni.zambon@unimib.it (G.Z.); m.smiraglia@campus.unimib.it (M.S.) \\ 2 Department of Physics, University of Milano-Bicocca, Piazza della Scienza 3, 20126 Milano, Italy; \\ eduardo.roman@mib.infn.it \\ * Correspondence: roberto.benocci@unimib.it; Tel.: +39-02-6448-2108
}

Received: 1 December 2017; Accepted: 30 January 2018; Published: 7 February 2018

Featured Application: The method discussed in this paper has applications in the context of predicting traffic noise in large urban environments. The system designed by the authors provides an accurate description of traffic noise by relying on measurements of road noise from few monitoring stations appropriately distributed over the zone of interest. A prescription is given of how to choose the location of the noise stations.

\begin{abstract}
Dynamap, a co-financed project by the European Commission through the Life+ 2013 program, aims at developing a dynamic approach for noise mapping that is capable of updating environmental noise levels through a direct link with a limited number of noise monitoring terminals. Dynamap is based on the idea of finding a suitable set of roads that display similar traffic noise behavior (temporal noise profile over an entire day) so that one can group them together into a single noise map. Each map thus represents a group of road stretches whose traffic noise will be updated periodically, typically every five minutes during daily hours and every hour during night. The information regarding traffic noise will be taken continuously from a small number of monitoring stations (typically 24) appropriately distributed over the urban zone of interest. To achieve this goal, we have performed a detailed analysis of traffic noise data, recorded every second from 93 monitoring stations randomly distributed over the entire urban area of the City of Milan. Our results are presented for a restricted area, the urban Zone 9 of Milan. We have separated the entire set of (about 2000) stretches into six groups, each one represented by a noise map, and gave a prescription for the locations of the future 24 monitoring stations. From our analysis, it is estimated that the mean overall error for each group of stretches (noise map), averaged over the $24 \mathrm{~h}$, is about $2 \mathrm{~dB}$.
\end{abstract}

Keywords: traffic noise; road clustering; noise monitoring stations; dynamic acoustic maps; error on acoustic maps

\section{Introduction}

In the last decade, distributed acoustic monitoring systems started to appear in urban contexts, due to lowering costs of electronic components and to cheaper and smaller hardware for data transfer. Triggered by the European Directive 2002/49/EC and connected to the assessment and management of environmental noise (END) [1], this interest has grown due to the awareness that noise maps represent a powerful tool for determining the population exposure to environmental noise. The recent END revision [2] has updated the current situation on the application of the END. Noise pollution continues to be a major health problem in Europe, with a host of health effects that can be summarized as follows: annoyance [3], sleep disorders with awakenings [4], learning impairment [5-7], and hypertension ischemic heart disease [8-10]. In this context, the END's prescription for noise maps and action plans, 
have prompted many efforts by the member states and the scientific community to high level study and propose new mitigation systems for the main sources of noise: road traffic [11,12], railway traffic [13,14], airports $[15,16]$, industrial centers $[17,18]$, plus other sources recognized as highly annoying $[19,20]$. In particular, mitigation measures in urban context need to be identified according to a realistic picture of noise distribution over urban areas. This requirement demands for real-time measurements and processing to assess the acoustic impact of noise sources.

A number of projects have been devoted to making extended noise measurements. To cite a few: the SENSEable Pisa project [21] was aimed at developing a network of noise sensors located at the residences of volunteer citizens to produce a detailed real-time acoustic overview of the territory. In the same way, the NoiseTube [22] and Smart Citizen [23] research projects proposed a participative approach to monitoring noise pollution by involving the citizenship. The Harmonica project [24] suggested the creation of a simple, a-dimensional noise index, closer to the feelings of the populations than the usual averaged indicators, similar to the ones used for air quality. Noisemote [25], a real-time service for environmental noise control based on wireless capabilities operates in such a way that sensors constantly monitor the environment by collecting data and sending real-time alerts if noise levels exceed the prescribed threshold. H.U.S.H. project [26] (Harmonization of Urban noise reduction Strategies for Homogeneous action plans) had the general goal of contributing to the harmonization of the national laws to the European ones for the noise management contained in Directive 49/2002, starting from the realization of a study and an intervention in the city of Florence, considered as a pilot case. The project QUADMAP [27], which stands for QUiet Areas Definition and Management in Action Plans, delivered a method and guidelines for the identification, delineation, characterization, improvement, and management of quiet areas in urban regions as per the Environmental Noise Directive 2002/49/EC.

The idea that a limited number of real-time noise measurements could be used to build up a noise map and could be representative of a large area found its realization in the Dynamap project [28]. Dynamap is a co-financed project by the European Commission through the Life+ 2013 program designed to produce dynamic noise maps within a large urban area. The method is described for a given zone in the city of Milan (Zone 9, illustrated in Figure 1), consisting of about 2000 road arches, using 24 continuous measuring stations [29].

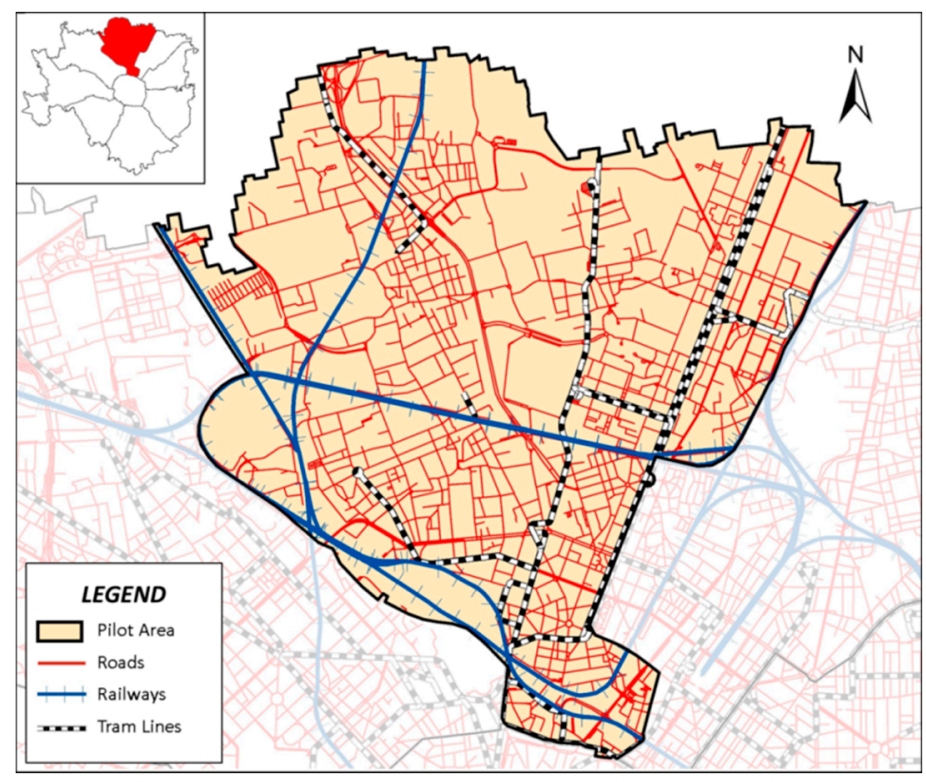

Figure 1. The Urban Zone 9 of the city of Milan, the pilot area chosen for the deployment of the acoustic sensors for Dynamap. The number of recording stations has been fixed at 24 . 
The idea that noise emission from a street generally depends on its activity, its use in the urban context rather than strictly from its geometric characteristics, suggested a different approach to monitoring sampling based on stratified sampling [30,31].

Therefore, our approach to road monitoring [32,33] followed this suggestion and aimed at optimizing the number of monitoring sites. Extensive comparisons between the stratified sampling by legislative road classification and that by mean cluster profiles are made in [34], wherein the authors describe the monitoring activities (including data collection managing) performed to characterize the road noise of the city and the procedure used to identify the best clustering method to statistically aggregate them in two clusters, depending on their hourly noise level profiles. Such an approach was also taken in [35]. For a complex urban context, the suitability of the mapping process is related to the fact that vehicle flow patterns are typically quite regular, allowing them to be classified using essentially two main clusters of different road traffic behaviors [36].

In Reference [37], the obtained clusters, based on a restricted traffic road noise sample, were tested to check for their normal distribution and "statistical independence" of the mean values. Such clusters were shown to be very robust in terms of cluster composition at different time scales. Noise level profiles had time resolutions of 60, 30, 20, 15, 10 and 5 min [38].

In References [39,40], each cluster was also cross-checked with non-acoustic information (e.g., rush hour traffic flow or average daily traffic volume) in order to assign each road segment to the correspondent noise cluster. The two clusters proved to be more efficient for the estimate of the mean LAeqd and LAeqn levels than those observed for the functional classification of roads because of a better correspondence between the statistical profiles and the measured sound sources [39].

The analysis of the distribution of a non-acoustic parameter (which depends on vehicular flows) within each cluster allows for the attribution of a specific noise profile for each road within the entire urban zone. In this way, entire road arches can be divided (for convenience of representation) into six groups to cover the entire area of interest [40]. Therefore, each group will be represented by its own dynamic noise map. In this paper, we discuss how to estimate the errors associated with each acoustic map. To start the process, four monitoring stations were planned to be installed for each group, selecting the most representative arches. The procedure for updating the pre-calculated six basic noise maps in the starting phase of Dynamap is discussed. The process is based on the average of noise level variations calculated at the monitoring stations, according to two different procedures. The absolute equivalent noise level at a given time interval for an arbitrary location in the urban pilot area could be obtained by properly summing the six acoustic maps updated values.

\section{Materials and Methods}

\subsection{The Equivalent Noise Level Clustering}

The analysis of hourly traffic noise measurements from the 93 sites distributed over the city of Milan have been performed using standard clustering techniques which has been described extensively in $[29,33,39]$. The analysis resulted in the identification of two clusters, here denoted as Clusters 1 and 2, which display similar time dependences. The results are shown in Figure 2, for the mean normalized acoustic equivalent levels $\bar{\delta}_{i k}$ for each cluster $k=1,2$ as a function of the hour $i$ of the day. Here, the choice to resort to normalized levels are justified by the non-homogeneity of monitoring conditions, such as the different distances from the road as well as the characteristics of the street itself.

These two clusters summarize the typical behavior by which roads can be divided into. In particular, Cluster 1 represents roads characterized by strong variations in equivalent levels between day and night periods and therefore in the corresponding traffic flow in these two periods. On the contrary, Cluster 2 presents fewer variations, which can be associated with a rather high traffic flow rate both during the day and night periods. 


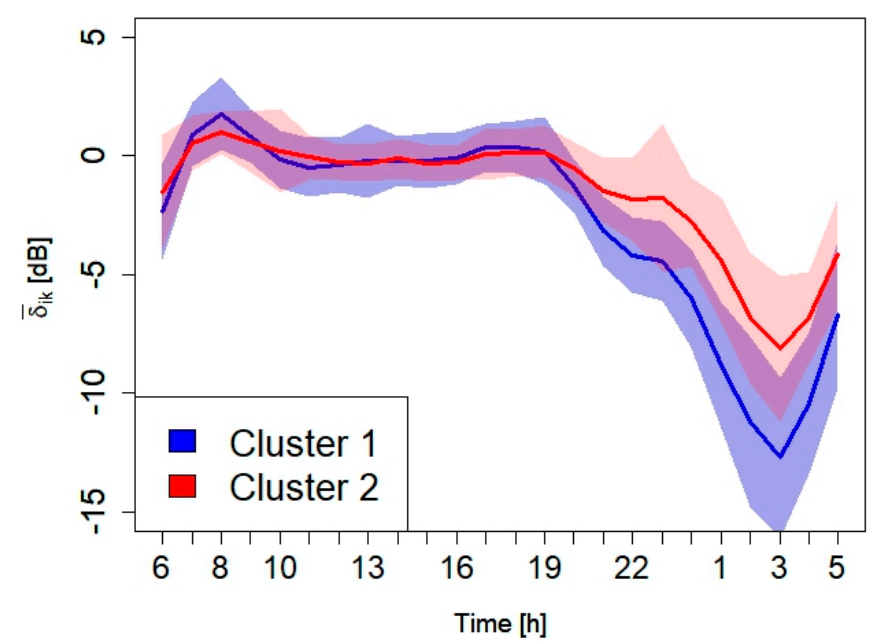

Figure 2. Mean cluster normalized equivalent level profiles (continuous lines), $\bar{\delta}_{i k}(\mathrm{~dB})$, for the two clusters, $k=(1,2)$, as a function of hour $i$ of the day (also indicated with the letter $h$ ). We show the corresponding dispersion of the hourly values within $\sqrt{2}$ standard deviation, $\sigma$ (colored bands). We will use also the notation $\delta_{\mathrm{C} 1}(h)$ and $\delta_{\mathrm{C} 2}(h)$ for the mean equivalent noise levels of Clusters 1 and 2 as a function of hour $h$. Cluster 1 has 56 elements and Cluster 2 has 37 components. Details on the measurements and analysis related to this figure are reported in $[29,33,39]$.

The data of which each cluster is made were not normally distributed over the entire day period, as shown by the Shapiro-Wilk test (SW) results reported in Figure 3 (the time intervals of $\delta_{i k}$ not satisfying the normal distribution for Clusters 1 and 2 fall below the red line in the plot, represented by $\alpha=0.05$ significance level). Therefore, we chose to represent the dispersion bands of the hourly values in Figure 2 with a $\sqrt{2}$ standard deviation, $\sigma$. According to Chebyshev's (Tchebycheff) inequality [41], which is valid for a wide class of probability distributions, this corresponds to a minimum of $50 \%$ of values lying within $\sqrt{2} \sigma$ of the mean (at least for those not satisfying the SW test).

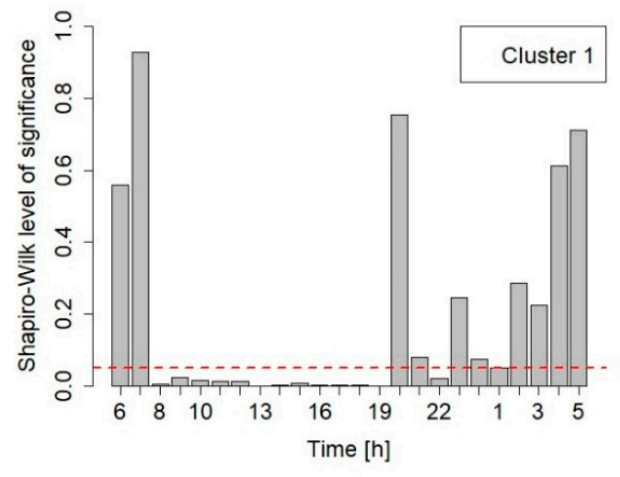

(a)

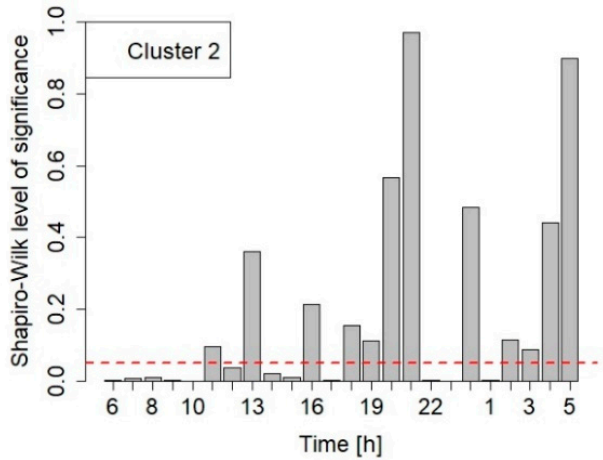

(b)

Figure 3. Shapiro-Wilk results for the normal distribution test of $\delta_{i k}$ for Cluster 1 (a) and Cluster 2 (b) The red line indicates the threshold at the $\alpha=0.05$ significance level.

\subsection{The Non-Acoustic Parameter and Its Distribution Function}

In order to predict traffic noise for a given road stretch, when a direct measurement is not practicable, we need to define a non-acoustic parameter, which we denote generically as $x$ and is related to model calculations of the traffic flow on that road stretch. Here, we have used the traffic model developed by the municipal agency for mobility, environment and territory (Agenzia Mobilità Ambiente e Territorio, AMAT), in charge of the transportation policy in the city of Milan. The model 
provides mean hourly values of traffic flow for each road stretch $n$ in the entire urban zone of Milan. The hourly behavior of the traffic noise for a given road stretch $\mathrm{n}$, characterized by a value $x_{n}$, can be described in terms of the distribution functions of the variable $x, P(x)$, obtained from the roads belonging to Clusters 1 and 2 . The corresponding distribution functions, denoted as $P_{1}(x)$ and $P_{2}(x)$, are shown in Figure 4, for the choice of $x$ given by the logarithm of the total daily traffic flow rate $x=\log \left(\mathrm{T}_{\mathrm{T}}\right)$. Other choices of $x$ lead to similar qualitative behavior $[39,40]$.

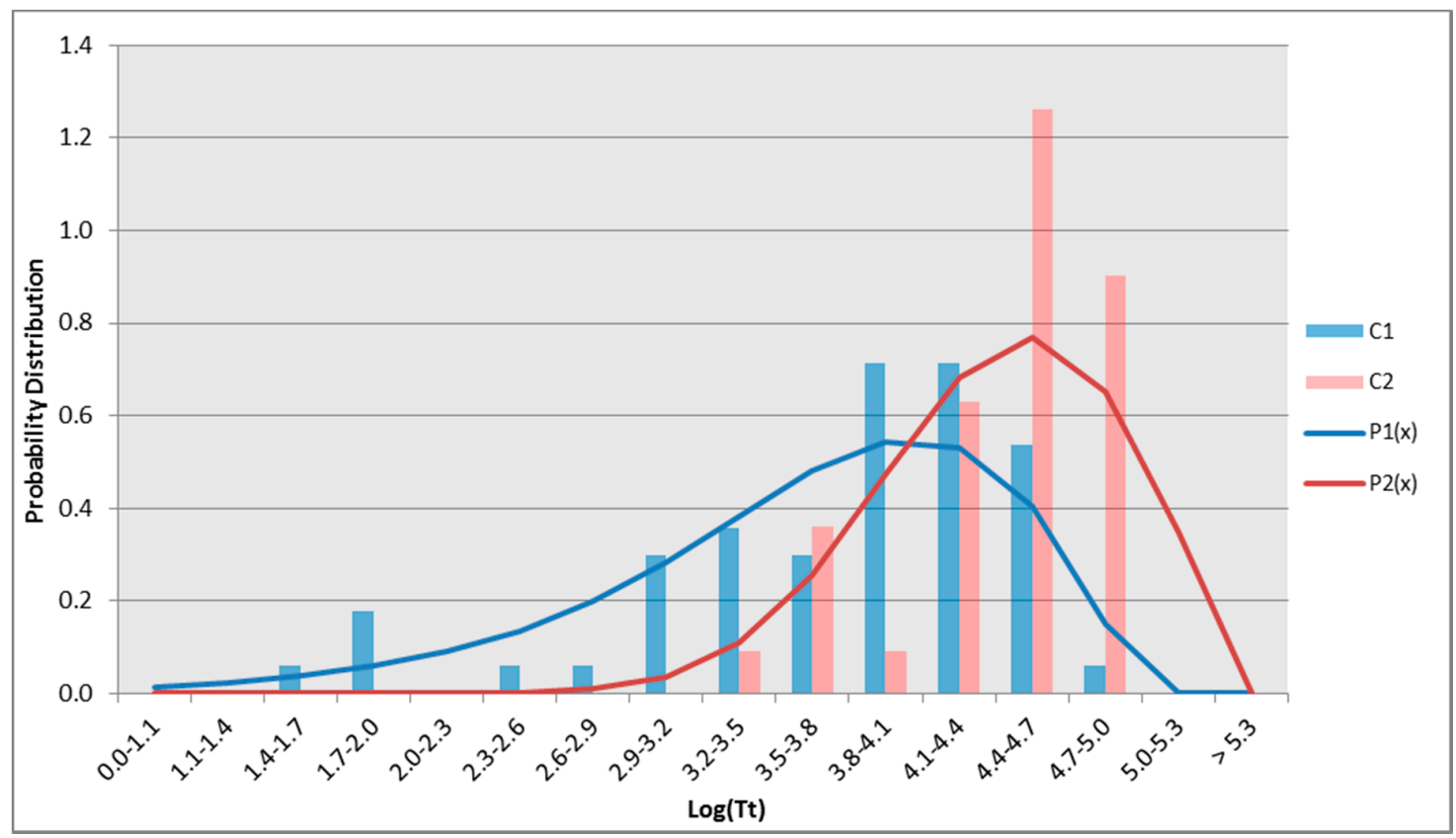

Figure 4. Distribution functions $P_{1}(x)$ and $P_{2}(x)$ for $x=\log \left(\mathrm{T}_{\mathrm{T}}\right)$ on Clusters 1 and 2 , respectively. The continuous lines represent logarithmic fits to the actual histograms using the cumulative distribution functions and are used here to accurately determine $\beta_{1,2}$ using Equation (1).

As one can see from Figure 3, there is a conspicuous overlap between the two distributions, suggesting that a sharp separation into two clusters is not possible in general. We conclude that a given value of $x$ has components in both clusters, meaning that the temporal evolution of the noise for a given road stretch is partly due to Cluster 1 and partly due to Cluster 2 . The idea of the method is to evaluate the probability $\beta_{1}$ that $x$ belongs to Cluster 1 and the probability $\beta_{2}=1-\beta_{1}$ that it belongs to Cluster 2. The corresponding values of $\beta$ are given by the following relations:

$$
\begin{aligned}
& \beta_{1}(x)=\frac{P_{1}(x)}{P_{1}(x)+P_{2}(x)} \\
& \beta_{2}(x)=\frac{P_{2}(x)}{P_{1}(x)+P_{2}(x)} .
\end{aligned}
$$

Using the values of $\beta_{1,2}$ we can predict the hourly variations $\delta_{x}(h)$ for a given value of $x$ according to

$$
\delta_{x}(h)=\beta_{1}(x) \delta_{\mathrm{C} 1}(h)+\beta_{2}(x) \delta_{\mathrm{C} 2}(h)
$$

with $\delta_{\mathrm{C} 1}(h)$ and $\delta_{\mathrm{C} 2}(h)$ representing the mean hourly values of the equivalent level (Figure 2 ) for both Clusters 1 and 2, respectively. The error made in using Equation (2) can be estimated (see also Section 3) by calculating the square deviation $\varepsilon^{2}$ of the prediction $\delta_{x}(h)$ from the measured values $\delta_{\text {meas }}(h)$, that is

$$
\varepsilon^{2}=\frac{1}{24} \sum_{h=1}^{24}\left[\delta_{x}(h)-\delta_{\text {meas }}(h)\right]^{2}
$$


One important requirement for the location of monitoring stations is that the corresponding road stretches, where they are positioned, have values of the non-acoustic parameter $x$ distributed uniformly over the typical range of values found in the urban zone under consideration (see Section 2.3). To check this for the 93 measurement locations, we have compared the distribution function of $x$ for Zone 9 (Z9) of Milan with the $P(x)$ obtained from the stretches where the noise measurements were performed. The results are shown in Figure 5, suggesting that the choice of sampling locations was appropriate. To be noted is that the latter has been fitted analytically from the $93 x$-values, which are more or less scattered over the same range of $x$ as the one for Z9. In Figure 5, we also compare the distribution $P(x)$ for the entire city of Milan with the one from Zone 9, clearly showing that the latter is a representative subset of the entire urban zone.

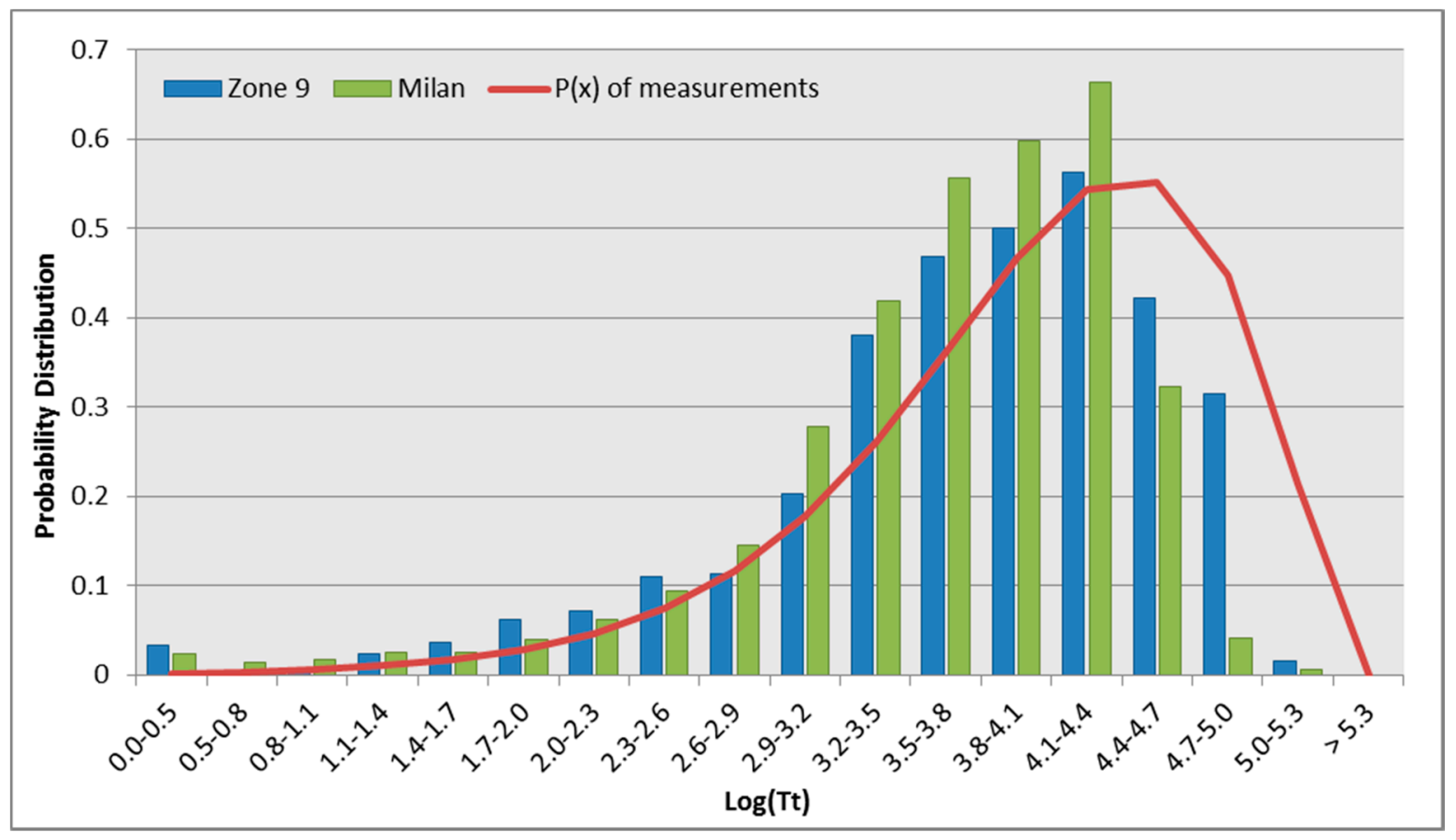

Figure 5. Distribution function $P(x)$ of $x=\log \left(\mathrm{T}_{\mathrm{T}}\right)$ for Zone 9 of Milan City (Blue Histogram), compared to the distribution of $x$ for the entire city of Milan (Green Histogram). The continuous line represents the same fitting procedure as in Figure 4, from the 93 road stretches where the noise measurements were performed.

\subsection{The Acoustic Maps and the Associated Groups of Road Stretches}

For the effective implementation of Dynamap, we have only 24 stations at our disposal. In this case, the station locations should not be chosen purely at random, but distributed in such a way as to approximate as much as possible the empirical distribution of $x$ from Z9 (see Figure 5). For this reason, we have divided the entire range of $x$ values from Z9 into (arbitrarily) 6 intervals, called groups, so that each one contains approximately the same number of road stretches, thus mimicking a uniform distribution of locations. The decision of taking six groups is dictated by practical reasons about the number of acoustic maps that will be handled in the actual implementation of Dynamap. It should be noted that, once the number of groups has been chosen, six in this case, the arbitrariness in the determination of the groups is removed. The corresponding groups of roads for $Z 9$ are displayed in Figure 6. 


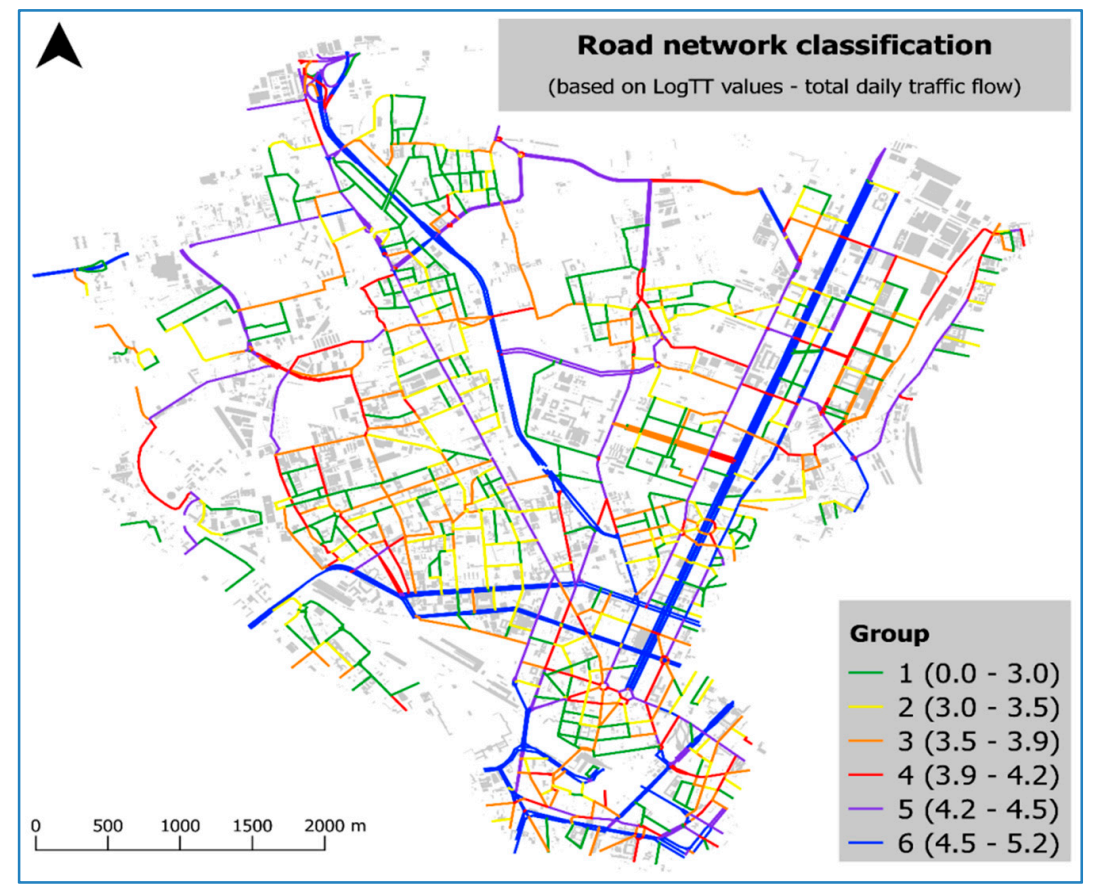

Figure 6. The six groups of road stretches (different colors) for the actual implementation of Dynamap. In the inset we report the intervals of $x$ values within each group.

Once we have determined the six groups of $x$ values (Table 1), the acoustic map of each group will be obtained from Equation (2) by using the mean values $\bar{\beta}_{1}$ and $\bar{\beta}_{2}$ within each group. They read

$$
\begin{aligned}
& \bar{\beta}_{1}\left(\bar{x}_{g}\right)=\frac{P_{1}\left(\bar{x}_{g}\right)}{P_{1}\left(\bar{x}_{g}\right)+P_{2}\left(\bar{x}_{g}\right)} \\
& \bar{\beta}_{2}\left(\bar{x}_{g}\right)=\frac{P_{2}\left(\bar{x}_{g}\right)}{P_{1}\left(\bar{x}_{g}\right)+P_{2}\left(\bar{x}_{g}\right)}
\end{aligned}
$$

where $\bar{x}_{g}$ is the mean value of $x$ within group $g$. The values of $\bar{\beta}_{1,2}$ for each group are reported in Table 1 (cf. Figure 6).

Table 1. Mean values of $\bar{\beta}_{1}$ and $\bar{\beta}_{2}$ for the six groups of $x=\log \left(\mathrm{T}_{\mathrm{T}}\right)$ within $\mathrm{Z9}$.

\begin{tabular}{ccccccc}
\hline Range of $\boldsymbol{x}$ & $\mathbf{0 . 0 - 3 . 0}$ & $\mathbf{3 . 0 - 3 . 5}$ & $\mathbf{3 . 5 - 3 . 9}$ & $\mathbf{3 . 9 - 4 . 2}$ & $\mathbf{4 . 2 - 4 . 5}$ & $\mathbf{4 . 5 - 5 . 2}$ \\
\hline$\overline{\boldsymbol{\beta}}_{1}$ & 0.99 & 0.81 & 0.63 & 0.50 & 0.41 & 0.16 \\
$\bar{\beta}_{2}$ & 0.01 & 0.19 & 0.37 & 0.50 & 0.59 & 0.84 \\
\hline
\end{tabular}

\section{Error Estimation for the Acoustic Maps}

In this section, we evaluate the mean statistical errors incurred within the present method for predicting the hourly equivalent noise levels of each acoustic map, i.e., for each group of road stretches. For convenience, the six groups will be denoted by $g=\left[g_{1}, g_{2}, g_{3}, g_{4}, g_{5}, g_{6}\right]$. To be noted is that each group represents a subset of road stretches within Z9 to which we associate the same equivalent noise variation $\delta_{x}$. In other words, all road stretches show the same dynamic noise behavior described by the group acoustic map. Local information regarding the single road stretch can be obtained according to the procedure discussed in Section 4.

In order to estimate the total statistical error of each map, represented here by the corresponding variances of the different contributions to the noise variations, we rely on the fact that, for $N$ 
uncorrelated random processes, the total variance of their sum, $\sigma_{N}^{2}$, is given by the sum of the individual variances. In our case, we have identified four processes whose fluctuations contribute to the total statistical error, $\sigma_{T}^{2}$, yielding the result

$$
\sigma_{T}^{2}=\sigma_{\text {pred }}^{2}+\sigma_{\text {stat }}^{2}+\sigma_{\text {comp }}^{2}+\sigma_{\text {sample }}^{2}
$$

corresponding to the intrinsic prediction error of the method, $\sigma_{\text {pred }}^{2}$, the statistical variance of the equivalent noise levels measured by the monitoring stations, $\sigma_{\text {stat }}^{2}$, the different cluster compositions for different time intervals, $\sigma_{c o m p}^{2}$, and the variance due to stratified sampling, $\sigma_{\text {sample }}^{2}$. In what follows, we discuss each term in Equation (5) separately.

\subsection{The Error Prediction of the Equivalent Noise Level: $\sigma_{\text {pred }}^{2}$}

This error has been discussed above with respect to Equation (3). In order to estimate it for each group $g$, we calculate the mean errors, $\bar{\varepsilon}_{1}^{2}$ and $\bar{\varepsilon}_{2}^{2}$, for the predictions of the monitoring station noise levels for Cluster 1 and Cluster 2, using Equation (3). Once these mean errors are known, we estimate the mean prediction error inside each group according to the relation

$$
\sigma_{\text {pred }}^{2}\left(\bar{x}_{g}\right)=\bar{\beta}_{1}\left(\bar{x}_{g}\right) \bar{\varepsilon}_{1}^{2}+\bar{\beta}_{2}\left(\bar{x}_{g}\right) \bar{\varepsilon}_{2}^{2}
$$

where $\bar{\beta}_{1}\left(\bar{x}_{g}\right)$ and $\bar{\beta}_{2}\left(\bar{x}_{g}\right)$ are given in Table 1.

\subsection{The Statistical Variance of Sampling Measurements from Clusters 1 and 2: $\sigma_{\text {stat }}^{2}$}

In the calculations, we have considered the mean noise levels from each measurement location in Cluster 1 and Cluster 2, $\bar{\sigma}_{1}^{2}$ and $\bar{\sigma}_{2}^{2}$, respectively. Therefore, for each group $g$ we have the following relation:

$$
\sigma_{\text {stat }}^{2}\left(\bar{x}_{g}\right)=\bar{\beta}_{1}\left(\bar{x}_{g}\right) \sigma_{1}^{2}+\bar{\beta}_{2}\left(\bar{x}_{g}\right) \sigma_{2}^{2} .
$$

\subsection{Cluster Compostion Error on Time Intervals Smaller than the Hour: $\sigma_{\text {comp }}^{2}$}

Our clustering calculations are based on hourly data of equivalent traffic noise. In order to have a guidance to define the updating time of the noise map, we investigated two time intervals shorter than the $1 \mathrm{~h}$ reference; for practical applications, we will deal with time intervals of $5 \mathrm{~min}, 15 \mathrm{~min}$, and $1 \mathrm{~h}$. Therefore, the question arises as to whether the composition (set of road stretches) belonging to each cluster remains the same, and, if it does not, how the differences are to be quantified. We have therefore repeated the clustering process for the $5 \mathrm{~min}$ and $15 \mathrm{~min}$ data and compared them with the hourly results in the following way. For each time interval $\tau=(5,15) \mathrm{min}$, we obtained the mean values $\delta_{\text {meas, }, \mathrm{Cl,2}(\tau)}(\tau)$ every $\tau$ mins, averaged over the roads belonging to Clusters 1 and 2 as given by the clustering analysis for time interval $\tau$. Then, we calculated the same mean quantities using the cluster composition obtained from the hourly clusters, $\delta_{\text {meas, }, \mathrm{C} 1,2(h)}(\tau)$. Finally, the mean-square differences were obtained:

$$
\sigma_{\text {comp }, \mathrm{C} 1,2}^{2}(\tau)=\frac{1}{N(\tau)} \sum_{t=1}^{N(\tau)}\left[\delta_{\text {meas }, \mathrm{C} 1,2(\tau)}(t)-\delta_{\text {meas }, \mathrm{C} 1,2(h)}(t)\right]^{2}
$$

where $N(\tau)=24(60 / \tau)$ is the number of data points within the $24 \mathrm{~h}$ period. In order to calculate the error associated with each group, we multiply each cluster variance in Equation (8) by the corresponding mean $\bar{\beta}_{1}\left(\bar{x}_{g}\right)$ and $\bar{\beta}_{2}\left(\bar{x}_{g}\right)$ for Clusters 1 and 2 , respectively:

$$
\sigma_{c o m p}^{2}\left(\bar{x}_{g}\right)=\bar{\beta}_{1}\left(\bar{x}_{g}\right) \sigma_{c o m p, C 1}^{2}(\tau)+\bar{\beta}_{2}\left(\bar{x}_{g}\right) \sigma_{c o m p, C 2}^{2}(\tau) .
$$




\subsection{Error Associated with the Stratified Sampling Method: $\sigma_{\text {sample }}^{2}$}

In stratified spatial sampling, the sample is split up into strata (sub-samples) in order to decrease variances in sample estimates, to use partly non-random methods applied to sub-groups or clusters, or to study strata individually [42]. The central limit theorem states that, given a sufficiently large sample size $n$, from a population of size $N$ with a finite level of variance $\sigma_{\text {pop }}^{2}$, the mean $\bar{x}$ of all samples taken from the same population will be approximately equal to the mean of the population (expected value). Furthermore, all of the samples will follow an approximate normal distribution pattern, with all variances $\sigma_{x}^{2}$ being approximately equal to the variance of the population divided by each sample's size $n$, that is $\sigma_{x}^{2}=\sigma_{p o p}^{2} / n$. The maximum error $\sigma_{\text {sample }}$, which is the largest expected deviation of the sample mean from the population mean with the stated confidence level $1-\alpha$ (for $1-\alpha=95 \%$, the amplitude of the Gaussian distribution is $Z_{\alpha} \sigma_{x}$ with $Z_{\alpha}=1.96$ ), is $\sigma_{\text {sample }}=Z_{\alpha} \sigma_{x}$. The minimum number of elements of a sample $n_{\min }$ for a correct estimation of the mean of the population within an accuracy $\pm \sigma_{\text {sample }}$ is

$$
n_{\text {min }}=Z_{\alpha}^{2} \sigma_{\text {pop }}^{2} / \sigma_{\text {sample }}^{2} \text {. }
$$

In general, $\sigma_{p o p}^{2}$ is unknown, so we used in its place the sample variance $\sigma_{x}^{2}$, i.e.,

$$
n_{\text {min }}=Z_{\alpha}^{2} \sigma_{x}^{2} / \sigma_{\text {sample }}^{2}
$$

In our case, the overall sample size consists of 192 measurements to be divided into each cluster. According to Equation (11), the actual expected deviation $\sigma_{\text {sample }}$ for the two clusters with a number of measurements, $n_{c 1}, n_{c 2}$, respectively, reads

$$
\sigma_{\text {sample }_{i}}=Z_{\alpha} \sigma_{i} / \sqrt{n_{c i}}(i=1,2)
$$

Figures 7-9 show the expected deviation $\sigma_{\text {sample }}$ calculated for a temporal discretization $\tau=(5,15,60)$ min.

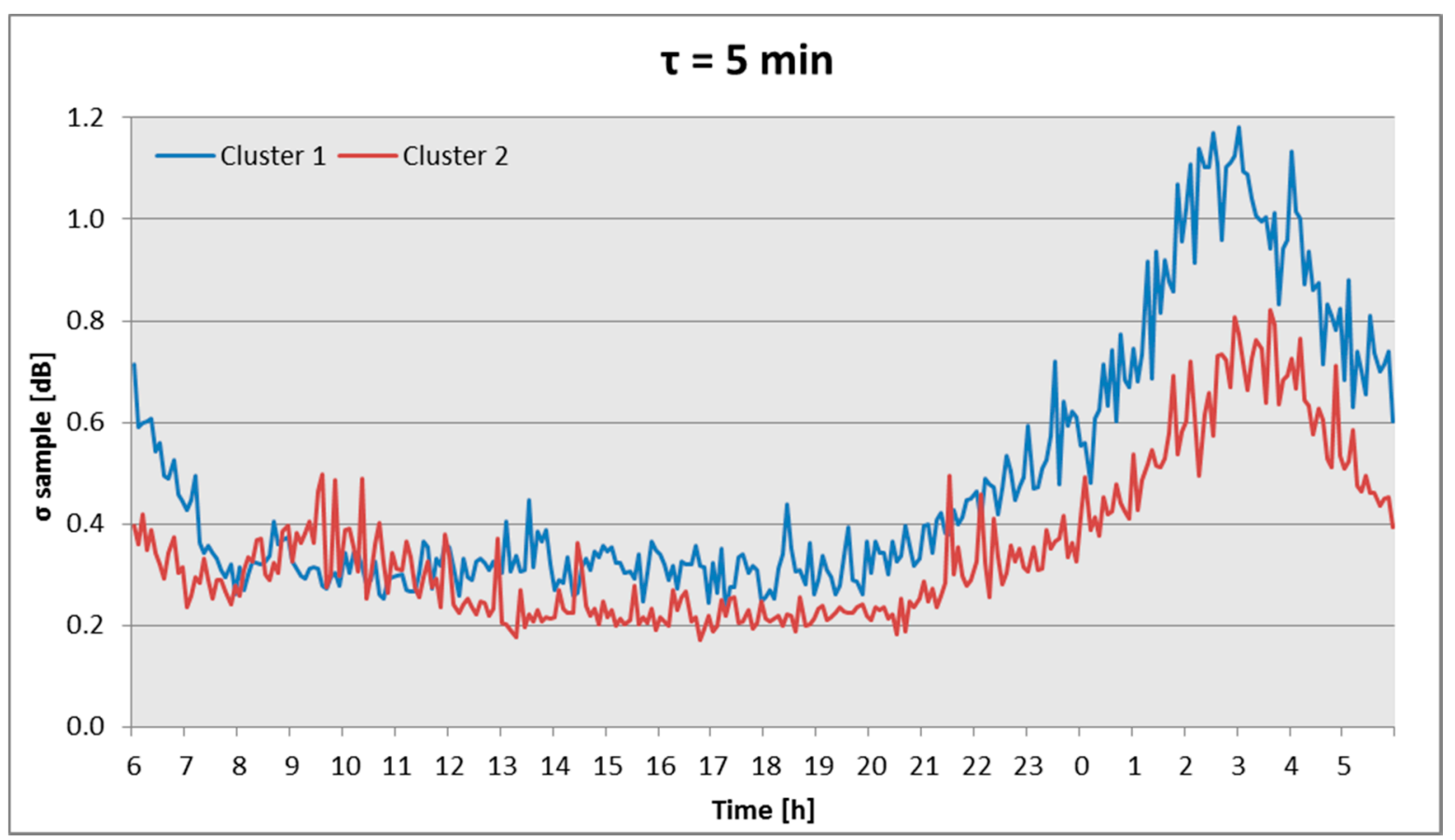

Figure 7. Expected deviation $\sigma_{\text {sample }}$ of the sample mean from the population mean calculated for a temporal discretization $\tau=5 \mathrm{~min}$. 


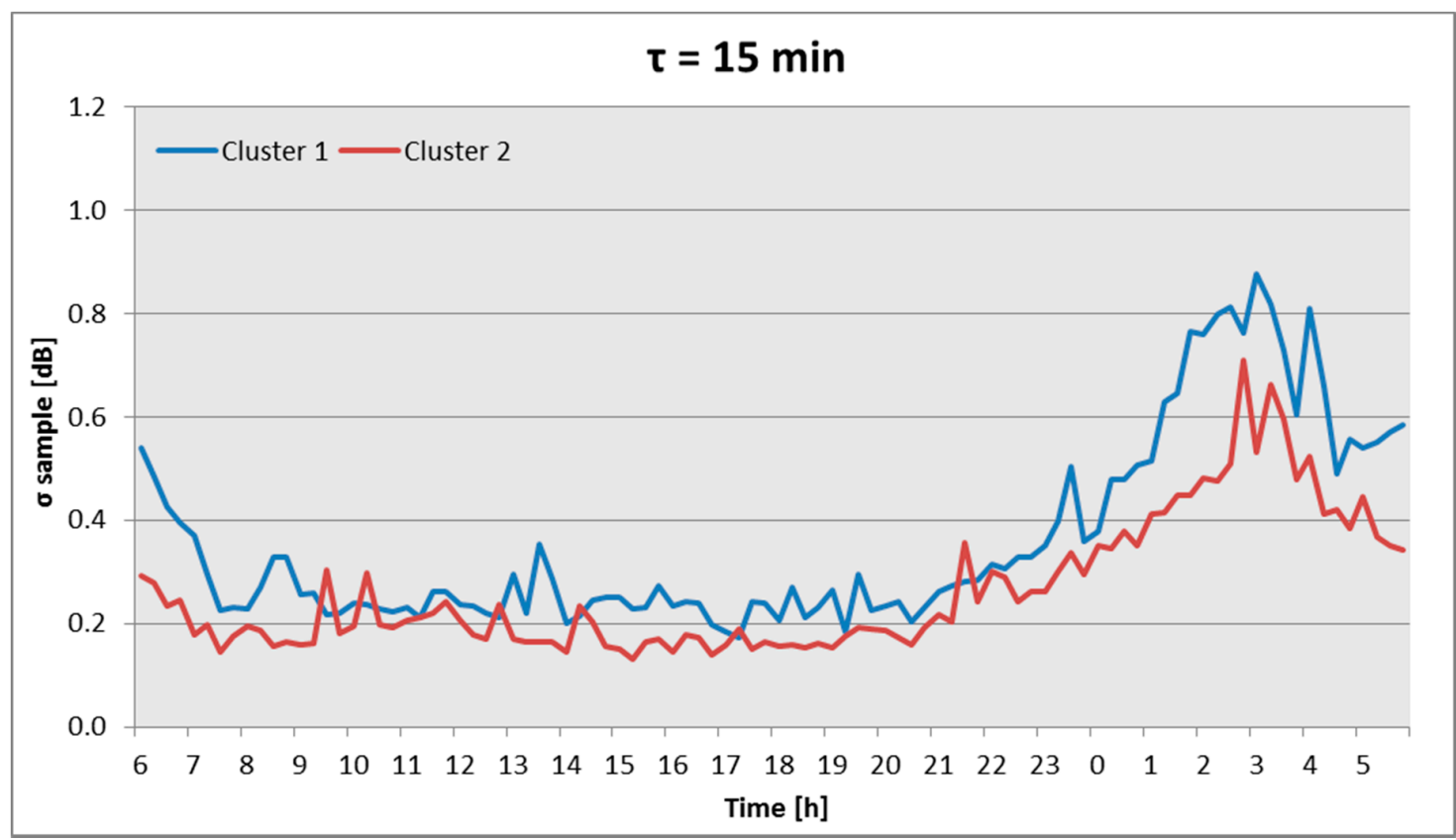

Figure 8. Expected deviation $\sigma_{\text {sample }}$ of the sample mean from the population mean calculated for a temporal discretization $\tau=15 \mathrm{~min}$.

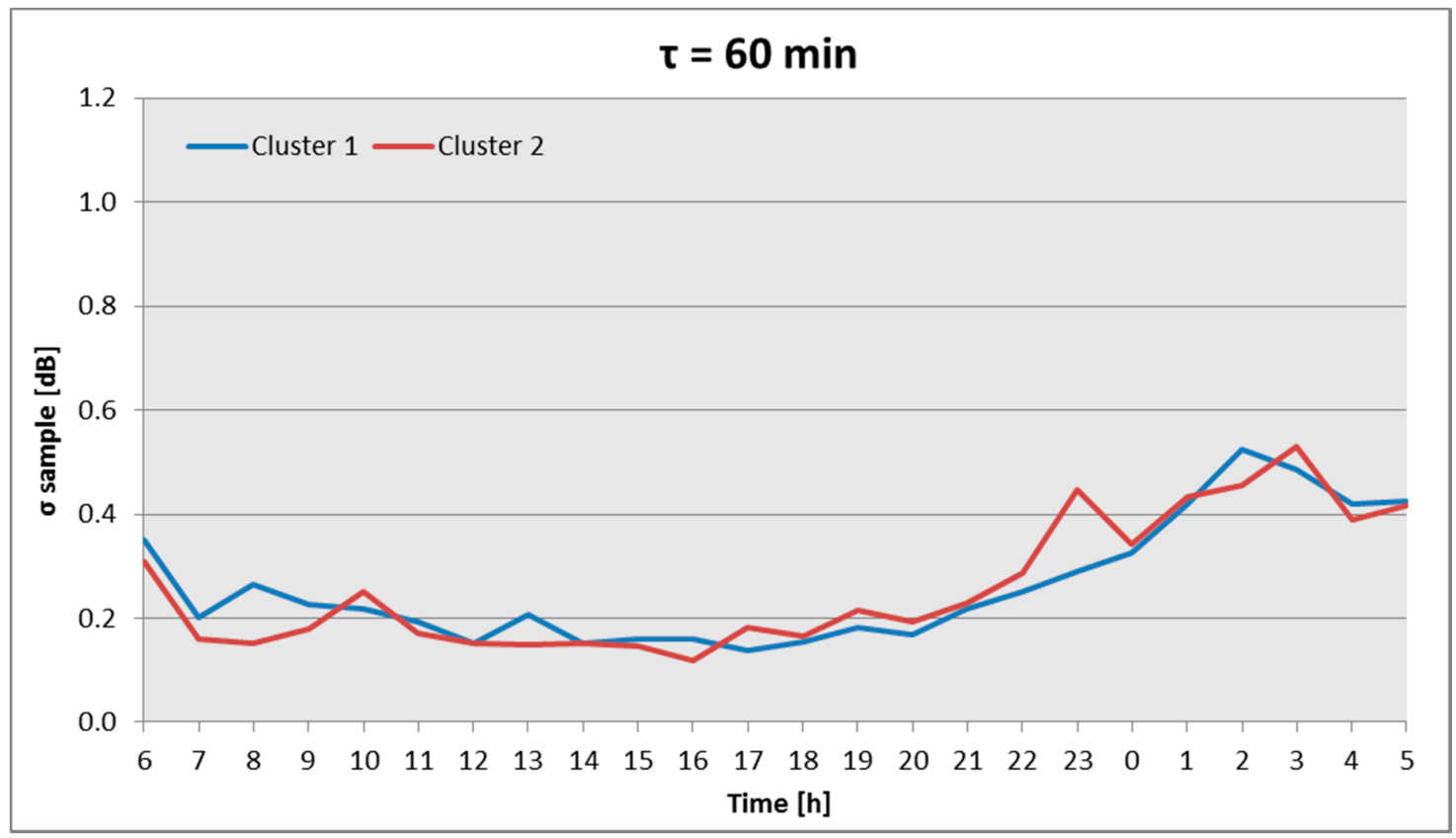

Figure 9. Expected deviation $\sigma_{\text {sample }}$ of the sample mean from the population mean calculated for a temporal discretization $\tau=60 \mathrm{~min}$.

To provide a homogeneous uncertainty, we chose different updating times for the day and night hours.

In Table 2, the mean expected deviation $\overline{\sigma_{\text {sample }}}$ calculated within the three time intervals $\mathrm{T}_{\mathrm{h}}$, defined as $\mathrm{T}_{\mathrm{h}}=(07: 00-21: 00),(21: 00-01: 00)$, and (01:00-07:00), for the three discretization times, defined as $\tau=(5,15,60) \mathrm{min}$ is reported for each cluster. The time interval subdivision allows us to estimate an overall mean $\overline{\sigma_{\text {sample }_{1}}}$ of $0.37 \mathrm{~dB}$ and an overall mean sample $\overline{\sigma_{\text {sample }}}$ of $0.33 \mathrm{~dB}$ for Clusters 1 and 2, respectively. As is apparent, the sampling error can be neglected as compared to those reported in 
Table 3. Since the stratified sampling method represents an intrinsic error due to the finite number of measurements, we take the same value (mean value) $\sigma_{\text {sample }}\left(\bar{x}_{g}\right)=0.35 \mathrm{~dB}$ for each group $g$.

Table 2. Mean expected deviation $\overline{\sigma_{\text {sample }}}$ calculated within the three time intervals used in this work $-\mathrm{T}_{\mathrm{h}}=(07: 00-21: 00),(21: 00-01: 00)$, and (01:00-07:00)—for the three discretization times $\tau=(5,15$, 60) min for both clusters. The average daily values are therefore $0.37 \mathrm{~dB}$ for $C_{1}$ and $0.33 \mathrm{~dB}$ for $C_{2}$.

\begin{tabular}{|c|c|c|c|c|c|c|}
\hline \multirow{2}{*}{ Interval } & \multirow{2}{*}{$\tau(\min )$} & \multicolumn{2}{|c|}{ Cluster 1} & \multicolumn{2}{|c|}{ Cluster 2} & \multirow{2}{*}{ Total $n^{\circ}$ of Measurements } \\
\hline & & $n^{\circ}$ Measurements & $\overline{\sigma_{\text {sample }_{1}}}(\mathrm{~dB})$ & $n^{\circ}$ Measurements & $\overline{\sigma_{\text {sample }_{2}}}(\mathrm{~dB})$ & \\
\hline 07:00-21:00 & 5 & 110 & 0.32 & 82 & 0.26 & \\
\hline 01:00-07:00 & 60 & 125 & 0.44 & 67 & 0.42 & \\
\hline
\end{tabular}

Table 3. Mean daily values of the error contributions to $\sigma_{T}(\mathrm{~dB})$ for each group (acoustic map) $g$. The different symbols correspond to the intrinsic prediction error of the method, $\sigma_{\text {pred }}$, the statistical variance of the equivalent noise levels measured by the monitoring stations, $\sigma_{\text {stat }}$, the different cluster compositions for different time intervals, $\sigma_{\text {comp }}$, and the error due to stratified sampling, $\sigma_{\text {sample }}$.

\begin{tabular}{ccccccc}
\hline Error/Group & $g_{\mathbf{1}}$ & $g_{\mathbf{2}}$ & $g_{\mathbf{3}}$ & $g_{4}$ & $g_{5}$ & $g_{\mathbf{6}}$ \\
\hline$\sigma_{\text {pred }}$ & 1.47 & 1.44 & 1.40 & 1.37 & 1.36 & 1.31 \\
$\sigma_{\text {stat }}$ & 1.53 & 1.47 & 1.40 & 1.35 & 1.32 & 1.22 \\
$\sigma_{\text {comp }}$ & 0.14 & 0.15 & 0.17 & 0.18 & 0.18 & 0.20 \\
$\sigma_{\text {sample }}$ & 0.35 & 0.35 & 0.35 & 0.35 & 0.35 & 0.35 \\
$\sigma_{T}$ & 2.16 & 2.09 & 2.02 & 1.96 & 1.94 & 1.83 \\
\hline
\end{tabular}

\subsection{Summary of Error Components for Each Group: $\sigma_{T}^{2}$}

We report in Table 3 the values obtained for the different error contributions in Equation (5) to the total error $\sigma_{T}$ for each group $g$.

The estimated uncertainty of about $2 \mathrm{~dB}$ represents a promising result as suggested in the Good Practice Guide for strategic noise mapping [43]. This result will be further investigated in the test and fault analysis phase of the project.

\section{Discussion on the Initialization of Dynamap and Its Implementation}

In this section, we discuss how Dynamap can be brought to operation from the very beginning. The 24 stations (indexes $i=1-24$ ) have been chosen so that there are 4 stations (index $j=1-4$ ) in each one of the six groups, indexed $\left(g_{1}, \ldots, g_{6}\right)$, that the pilot Zone 9 of Milan has been divided into (see Figure 10). We can see, for example, that $(i=3,16,19,24)$ belong to group $g_{1}$. For each group $g$, we then have the correspondence of $(g, j)$ with $i$ using the notation $\mathrm{M}(g, j)=i$. In this example, correspondence is expressed as follows: $\mathrm{M}(1,1)=3, \mathrm{M}(1,2)=16, \mathrm{M}(1,3)=19$, and $\mathrm{M}(1,4)=24$. 

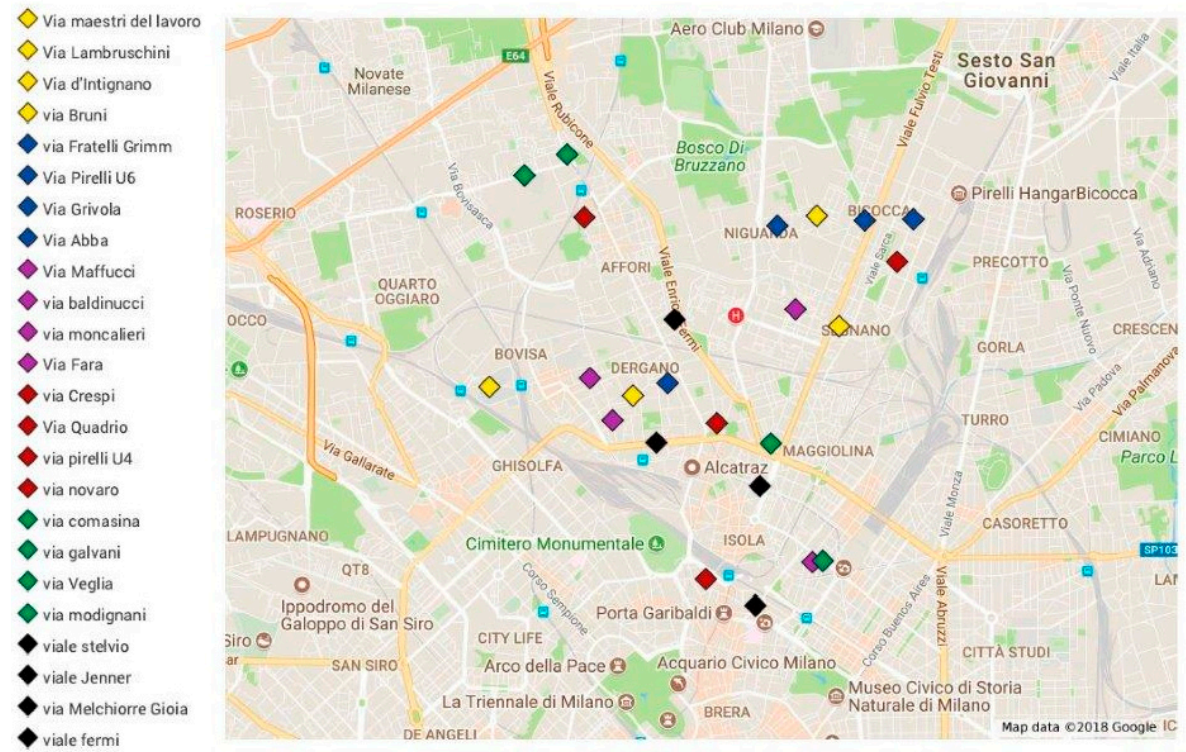

Figure 10. Locations of 24 monitoring noise stations on Z9. The inset on the left side of the figure reports the names of the streets of each monitoring station. The same color refers to stations belonging to the same group $g$.

\subsection{Starting Operations of Dynamap from Four Monitoring Stations in Each Group $g: \delta_{g, j}^{\tau}(t)$}

An acoustic map has been associated with each group $g$, so that all road stretches within a group are represented by the same acoustic map. Operatively, each station $i$ records a noise signal at a $30 \mathrm{~ms}$ resolution, which will be integrated, after filtering the anomalous events, in a $1 \mathrm{~s}$ equivalent noise level $[44,45]$. The signal then needs further integration to obtain $L_{e q \tau, i}$ over a predefined temporal interval $\tau(\tau=51,560 \mathrm{~min})$. Thus, we get $24 \mathrm{~L}_{\mathrm{eq} \tau, i}$ values every $\tau \mathrm{min}$, each one corresponding to a recording station $i$. To update the acoustic maps, we deal with variations $\delta_{g, j}^{\tau}(t)$, where the time $t$ is discretized as $t=n \tau$ and $n$ is an integer, defined according to

$$
\delta_{g, j}^{\tau}(t)=\mathrm{L}_{\mathrm{eq} \tau M(g, j)}(t)_{(\text {measured })}-\mathrm{L}_{\mathrm{eqref} M(g, j)}\left(T_{r e f}\right)_{(\text {calculated })}
$$

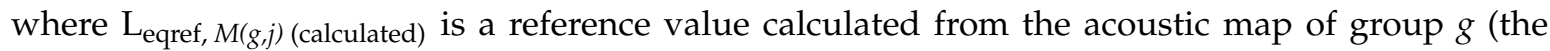
CADNA model) at the time interval $\mathrm{T}_{\text {ref }}=(08: 00-09: 00)$ at the point corresponding to the position of the $M(g, j)$-th station. The CADNA model provides mean hourly $L_{\mathrm{eq}}$ values over the entire city of Milan at a resolution of $20 \mathrm{~m}$ given a set of input traffic flow data, thus representing a reference static acoustic map. Here, we have chosen the reference time $T_{\text {ref }}=(08: 00-09: 00)$ for convenience, since it displays rush-hour type of behavior. The temporal ranges within the day are conventionally chosen as

$$
\begin{aligned}
& \tau=5 \min \text { for }(07: 00-21: 00) ; \\
& \tau=15 \min \text { for }(21: 00-01: 00) ; \\
& \tau=60 \text { min for }(01: 00-07: 00) .
\end{aligned}
$$

Once all the $\delta_{g, j}^{\tau}(t)$ values have been obtained, the six acoustic maps can be updated corresponding to each group $g$ by averaging the variations in Equation (13) over the four values $j$ in each group, according to

$$
\delta_{g}^{\tau}(t)=\frac{1}{4} \sum_{j=1}^{4} \delta_{g, j}^{\tau}(t) .
$$

The variations $\delta_{g, j}^{\tau}(t)$ originated from the $(g, j)$-th station must remain bound within the group Acceptance Interval (A.I.) $\left[Q_{1, g}^{\tau}(t)-1.5 \cdot \operatorname{IQR}_{g}^{\tau}(t), Q_{3, g}^{\tau}(t)+1.5 \cdot \operatorname{IQR}_{g}^{\tau}(t)\right]$, where $\mathrm{IQR}_{g}^{\tau}$ is the interquartile range obtained as the difference between the 75th $\left(Q_{3, g}^{\tau}(t)\right)$ and 25th $\left(Q_{1, g}^{\tau}(t)\right)$ percentiles 
calculated at the same time $t$ (of duration time $\tau$ ) of the day for all $\delta_{g, j}^{\tau}(t)$. These quantities can be obtained initially from the data recorded over the few previous working days (running or moving averages) during the operation of Dynamap. In the case in which a variation $\delta_{g, j}^{\tau}(t)$ falls outside the group A.I., the contribution of the $(g, j)$-th station is considered to be an outlier and it is not included in Equation (14). Then, the average is performed over the remaining active stations. In this way, the acoustic maps can be updated. In the extreme case in which more than 12 of the stations of the entire network (for instance two stations per group fail to remain within the A.I.) have exceeded their A.I.s, we are in the presence of a global network extreme event, so their data cannot be rejected but need to be included in the updating procedure of the maps. The number of excluded stations (here initially taken as 12) will be reconsidered during the development of Dynamap.

\subsection{Clustering of the 24 Recording Stations: $\delta_{C 1,2}^{\tau}(t)$}

In the following, we discuss a second procedure for updating the acoustic maps based on the two-cluster expansion scheme, which should be more accurate as it uses all the 24 stations to determine $\delta_{g}^{\tau}(t)$ simultaneously. The clustering method cannot be implemented until a sufficient amount of noise data from the 24 stations have been recorded. That is, from each station, we need to record $\mathrm{L}_{\mathrm{eq} \tau, i}(t)$ and obtain sufficiently accurate mean values for each interval of time $\tau$. Then, the clustering calculation can be performed.

Once the compositions of Clusters 1 and 2 have been found (meaning that there are $N_{1}$ stations in Cluster $1, k_{1}=\left(1, \ldots, N_{1}\right)$, and $N_{2}$ stations in Cluster $2, k_{2}=\left(1, \ldots, N_{2}\right)$, such that $\left.N_{1}+N_{2}=24\right)$, we need to rearrange the variations obtained from Equation (14) according to the indices $C_{1, k 1}$ and $C_{2, k 2}$, which we denote as $\delta_{C 1, k 1}^{\tau}(t)$ and $\delta_{C 2, k 2}^{\tau}(t)$ within each cluster, $C_{1}$ and $C_{2}$. Then, we calculate the mean variations, $\delta_{C 1}^{\tau}(t)$ and $\delta_{C 2}^{\tau}(t)$, for each cluster according to,

$$
\begin{aligned}
& \delta_{C 1}^{\tau}(t)=\frac{1}{N_{1}} \Sigma_{k 1=1}^{N_{1}} \delta_{C 1, k 1}^{\tau}(t) \\
& \delta_{C 2}^{\tau}(t)=\frac{1}{N_{2}} \Sigma_{k 2=1}^{N_{2}} \delta_{C 2, k 2}^{\tau}(t)
\end{aligned}
$$

where $C_{1, k 1}$ and $C_{2, k 2}$ are the $N_{1}$ and $N_{2}$ indices of stations belonging to Cluster 1 and Cluster 2, respectively. Here, the allowed ranges of variation of $\left(\delta_{C 1, k 1}^{\tau}(t), \delta_{C 2, k 2}^{\tau}(t)\right)$ are (compared to Equation (14)) similarly determined using $\left[Q_{1, C 1,2}^{\tau}(t)-1.5 \cdot \operatorname{IQR}_{C 1,2}^{\tau}(t), Q_{3, C 1,2}^{\tau}(t)+1.5 \cdot \operatorname{IQR}_{C 1,2}^{\tau}(t)\right]$, calculated for all stations $\left(k_{1}, k_{2}\right)$ within each cluster, $C_{1}$ and $C_{2}$, respectively. Then, the mean variation $\delta_{g}^{\tau}(t)$ associated with each group $g$ can be calculated using the formula

$$
\delta_{g}^{\tau}(t)=\bar{\beta}_{1}\left(\bar{x}_{g}\right) \delta_{C 1}^{\tau}(t)+\bar{\beta}_{2}\left(\bar{x}_{g}\right) \delta_{C 2}^{\tau}(t)
$$

where the parameters $\bar{\beta}_{1}\left(\bar{x}_{g}\right)$ and $\bar{\beta}_{2}\left(\bar{x}_{g}\right)$ for each group $g$ are reported in Table 1 for the entire city of Milan. Here, the value $\bar{x}_{g}$ represents the mean non-acoustic parameter associated with group $g$, and $\bar{\beta}_{1}\left(\bar{x}_{g}\right), \bar{\beta}_{2}\left(\bar{x}_{g}\right)$ the corresponding probabilities to belong to Clusters 1 and 2, respectively. Again, in the extreme case in which more than 12 of the stations of the entire network have exceeded their A.I.'s (for instance 6 stations per cluster fail to remain within their A.I.'s), we are in the presence of a global network extreme event, so their data cannot be rejected but need to be included in the updating procedure of the maps. The number of excluded stations (here initially taken as 12) will be reconsidered during the development of Dynamap.

\subsection{Leq at Time t for Arbitrary Receiver Point a: Leq $\tau_{\tau}^{a}(t)$}

Let us discuss next the way in which the absolute level $L e q_{\tau}^{a}(t)$ at time $t$ for an arbitrary location point $a$ can be obtained from the measured values of $\delta_{g}^{\tau}(t)$ using either Equation (14) or Equation (16). The first quantity we need to know is the value of $\mathrm{L}_{\text {eqref }(\mathrm{g}, a)}$ at the point $a$ due to the noise produced by roads in the group $g$, which is provided by the calculated (CADNA) acoustic base map. The absolute 
level $\operatorname{Leq} q_{\tau}^{a}(t)$ at location $a$ at time $t=n \tau$ can then be obtained by properly adding the contribution of each base map with its variation $\delta_{g}^{\tau}$ :

$$
\operatorname{Leq}_{\tau}^{a}(t)=10 \cdot \log \sum_{g=1}^{6} 10^{\frac{\mathrm{L}_{\text {eqref }(g, a)}+\delta_{g}^{\tau}(t)}{10}} .
$$

This operation provides what we called the "scaled map" (dynamic map). In Figure 11, the working scheme procedure of Dynamap is illustrated. The process includes the data collection from field noise monitoring terminals (NMTs), the scaling of the basic noise maps, and finally their sum to achieve the updated scaled noise map of the entire area.

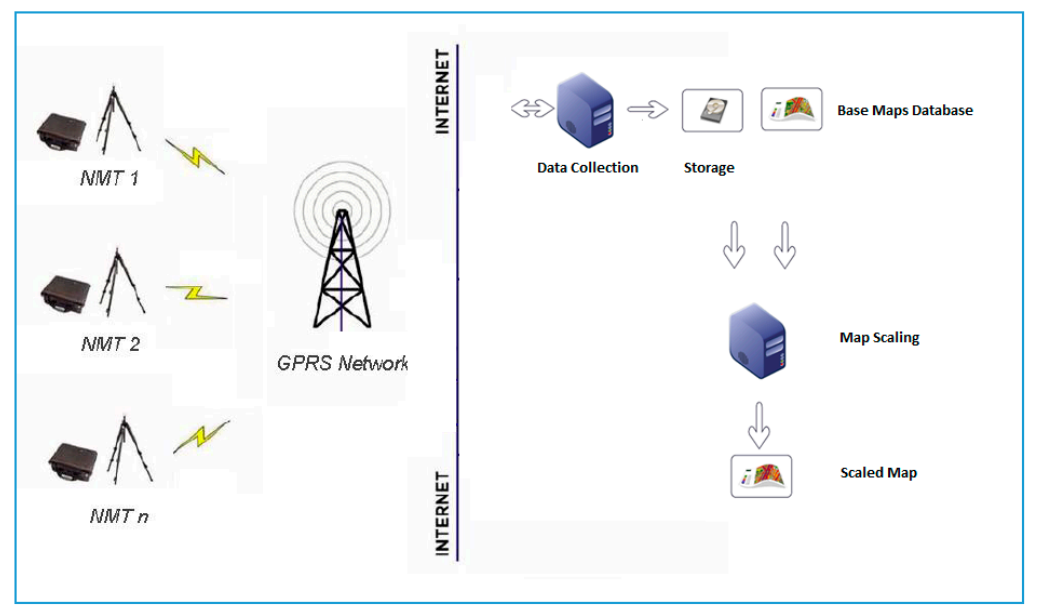

Figure 11. Schematic illustration of Dynamap working operation: data collection and storage from field noise monitoring terminals (NMTs), the scaling of the basic noise maps according to stored data, and the sum of scaled basic maps of each group $g$ to produce the updated scaled noise map of the entire area. GPRS: General Packet Radio Service.

\subsection{An Example of a Dynamap Snapshot}

In Figure 12 we illustrate an example of a scaled noise map taken as a snapshot of a sequence of evolving maps [28].

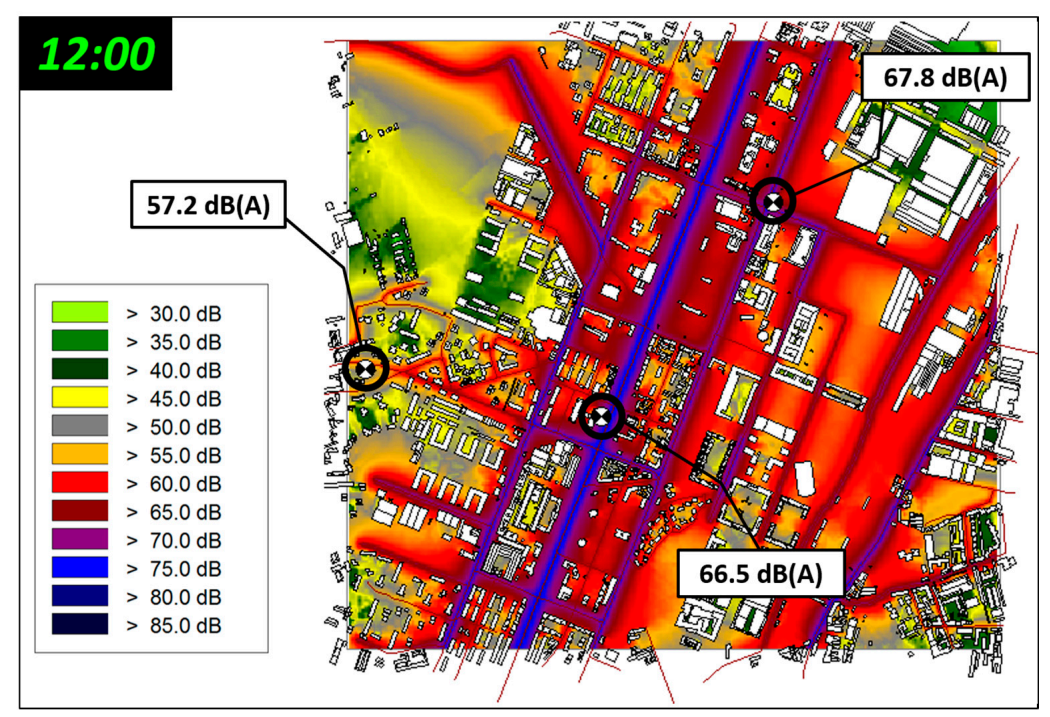

Figure 12. Illustration of a typical outcome of Dynamap showing in different colors different noise levels as indicated in the inset. In the plot, we show the location of three monitoring stations (black circles). 


\section{Conclusions}

We have described a method for predicting traffic noise in large urban environments. The system designed provides an accurate description of traffic noise by relying on measurements of road noise from a few monitoring stations appropriately distributed over the zone of interest.

In particular, we have discussed a procedure for starting and implementing the six acoustic maps (one for each group g) of Dynamap for Zone 9 in the City of Milan. This procedure considers three time intervals during the day-07:00-21:00, 21:00-01:00 and 01:00-07:00—associated with three discretization times-5, 15 and $60 \mathrm{~min}$, respectively. We have presented two methods for evaluating the variations $\delta_{g}^{\tau}(t)[\mathrm{dB}]$, one in which their average is performed over the four stations within each group $g$ and a second method that uses the corresponding values $\bar{\beta}_{1}\left(\bar{x}_{g}\right)$ and $\bar{\beta}_{2}\left(\bar{x}_{g}\right)$ for each group $g$. We have presented a general formula for obtaining the absolute level $L e q_{\tau}^{a}(t)$ at time $t$ for the update time $\tau$ at an arbitrary receiver point a (scaled map), and we have estimated the total errors associated with each map by including the possible uncertainties intrinsic to the model.

Acknowledgments: This research has been partially funded by the European Commission under project LIFE13 ENV/IT/001254 Dynamap.

Author Contributions: Giovanni Zambon conceived and planned the Dynamap project, H. Eduardo Roman and Roberto Benocci performed the statistical and error analysis on the data, and Maura Smiraglia contributed to the data analysis.

Conflicts of Interest: The authors declare no conflict of interest.

\section{References}

1. EU Directive. Directive 2002/49/EC of the European parliament and the Council of 25 June 2002 relating to the assessment and management of environmental noise. Off. J. Eur. Commun. 2002, 12, L189.

2. European Commission. Report from the Commission to the European Parliament and the Council on the Implementation of the Environmental Noise Directive in Accordance with Article 11 of Directive 2002/49/EC. COM/2017/0151 Final; European Commission: Brussels, Belgium, 2017.

3. Miedema, H.M.E.; Oudshoorn, C.G.M. Annoyance from transportation noise: Relationships with exposure metrics DNL and DENL and their confidence intervals. Environ. Health Perspect. 2001, 109, 409-416. [CrossRef] [PubMed]

4. Muzet, A. Environmental noise, sleep and health. Sleep Med. Rev. 2007, 11, 135-142. [CrossRef] [PubMed]

5. Hygge, S.; Evans, G.W.; Bullinger, M. A prospective study of some effects of aircraft noise on cognitive performance in schoolchildren. Psychol. Sci. 2002, 13, 469-474. [CrossRef] [PubMed]

6. Lercher, P.; Evans, G.W.; Meis, M. Ambient noise and cognitive processes among primary schoolchildren. Environ. Behav. 2003, 35, 725-735. [CrossRef]

7. Chetoni, M.; Ascari, E.; Bianco, F.; Fredianelli, L.; Licitra, G.; Cori, L. Global noise score indicator for classroom evaluation of acoustic performances in LIFE GIOCONDA project. Noise Mapp. 2016, 3, $157-171$. [CrossRef]

8. Dratva, J.; Phuleria, H.C.; Foraster, M.; Gaspoz, J.M.; Keidel, D.; Künzli, N.; Liu, L.J.; Pons, M.; Zemp, E.; Gerbase, M.W.; et al. Transportation noise and blood pressure in a population-based sample of adults. Environ. Health Perspect. 2012, 120, 50-55. [CrossRef] [PubMed]

9. Babisch, W.; Beule, B.; Schust, M.; Kersten, N.; Ising, H. Traffic noise and risk of myocardial infarction. Epidemiology 2005, 16, 33-40. [CrossRef] [PubMed]

10. Babisch, W.; Swart, W.; Houthuijs, D.; Selander, J.; Bluhm, G.; Pershagen, G.; Dimakopoulou, K.; Haralabidis, A.S.; Katsouyanni, K.; Davou, E.; et al. Exposure modifiers of the relationships of transportation noise with high blood pressure and noise annoyance. J. Acoust. Soc. Am. 2012, 132, 3788-3808. [CrossRef] [PubMed]

11. Morley, D.W.; de Hoogh, K.; Fecht, D.; Fabbri, F.; Bell, M.; Goodman, P.S.; Elliott, P.; Hodgson, S.; Hansell, A.L.; Gulliver, J. International scale implementation of the CNOSSOS-EU road traffic noise prediction model for epidemiological studies. Environ. Pollut. 2015, 206, 332-341. [CrossRef] [PubMed] 
12. Ruiz-Padillo, A.; Ruiz, D.P.; Antonio, J.; Torija, A.J.; Ramos-Ridao, Á. Selection of suitable alternatives to reduce the environmental impact of road traffic noise using a fuzzy multi-criteria decision model. Environ. Impact Assess. Rev. 2016, 61, 8-18. [CrossRef]

13. Licitra, G.; Fredianelli, L.; Petri, D.; Vigotti, M.A. Annoyance evaluation due to overall railway noise and vibration in Pisa urban areas. Sci. Total Environ. 2016, 568, 1315-1325. [CrossRef] [PubMed]

14. Bunn, F.; Trombetta Zannin, P.H. Assessment of railway noise in an urban setting. Appl. Acoust. 2016, 104, 16-23. [CrossRef]

15. Gagliardi, P.; Fredianelli, L.; Simonetti, D.; Licitra, G. ADS-B System as a Useful Tool for Testing and Redrawing Noise Management Strategies at Pisa Airport. Acta Acust. United Acust. 2017, 103, 543-551. [CrossRef]

16. Iglesias-Merchan, C.; Diaz-Balteiro, L.; Soliño, M. Transportation planning and quiet natural areas preservation: Aircraft overflights noise assessment in a National Park. Transp. Res. Part D Transp. Environ. 2015, 41, 1-12. [CrossRef]

17. Kephalopoulos, S.; Paviotti, M.; Anfosso Ledee, F.; Jones, N. Advances in the development of common noise assessment methods in Europe: The CNOSSOS-EU framework for strategic environmental noise mapping. Sci. Total Environ. 2014, 482, 400-410. [CrossRef] [PubMed]

18. Morel, J.; Marquis-Favre, C.; Gille, L.A. Noise annoyance assessment of various urban road vehicle pass-by noises in isolation and combined with industrial noise: A laboratory study. Appl. Acoust. 2016, 101, 47-57. [CrossRef]

19. Gallo, P.; Fredianelli, L.; Palazzuoli, D.; Licitra, G.; Fidecaro, F. A procedure for the assessment of wind turbine noise. Appl. Acoust. 2016, 114, 213-217. [CrossRef]

20. Michaud, D.S.; Feder, K.; Keith, S.E.; Voicescu, S.A.; Marro, L.; Than, J.; Guay, M.; Denning, A.; McGuire, D.; Bower, T.; et al. Exposure to wind turbine noise: Perceptual responses and reported health effects. J. Acoust. Soc. Am. 2016, 139, 1443-1454. [CrossRef] [PubMed]

21. Dustlab. SENSEable Pisa Project. 2011. Available online: http://senseable.it/ (accessed on 22 December 2017).

22. BrusSense. Noisetube Project. 2009. Available online: http:/ / www.noisetube.net (accessed on 22 December 2017).

23. FabLab Bcn. Smart Citizen Project. 2012. Available online: https://smartcitizen.me/ (accessed on 22 December 2017).

24. Bruitparif. Harmonica Project. 2011. Available online: http://www.noiseineu.eu/ (accessed on 22 December 2017).

25. Bluewave. Noisemote System. 2010. Available online: http:/ /www.noisemote.com (accessed on 22 December 2017).

26. Project H.U.S.H. 2008. Available online: http://www.hush-project.eu/en/index.html (accessed on 22 December 2017).

27. QUADMAP. 2012. Available online: http://www.quadmap.eu/ (accessed on 22 December 2017).

28. Dynamap. 2014. Available online: http:/ / www.life-dynamap.eu/ (accessed on 22 December 2017).

29. Zambon, G.; Benocci, R.; Bisceglie, A.; Roman, H.E.; Bellucci, P. The LIFE DYNAMAP project: Towards a procedure for dynamic noise mapping in urban areas. Appl. Acoust. 2017, 124, 52-60. [CrossRef]

30. Barrigon Morillas, J.M.; Gomez Escobar, V.; Méndez Sierra, J.A.; Vílchez Gomez, R. Study of noise in a small Spanish Town. Int. J. Acoust. Vib. 2002, 7, 231-237. [CrossRef]

31. Romeu, J.; Jimenez, S.; Genescà, M.; Pamies, T.; Capdevila, R. Spatial sampling for night levels estimation in urban environments. J. Acoust. Soc. Am. 2006, 120, 791-800. [CrossRef] [PubMed]

32. Angelini, F.; Zambon, G.; Salvi, D.; Zanaboni, W.; Smiraglia, M. Traffic noise monitoring in the city of Milan: Construction of a representative statistical collection of acoustic trends with different time resolutions. In Proceedings of the 23rd International Congress on Sound and Vibration, Florence, Italy, 12-16 July 2015.

33. Angelini, F.; Bisceglie, A.; Brambilla, G.; Gallo, V.; Zambon, G. Campionamento spaziale stratificato per il rumore da traffico stradale: Un'applicazione alla rete viaria di Milano (Stratified spatial sampling of road traffic noise: A case study of the road network in Milan). In Proceedings of the Associazione Italiana di Acustica (AIA), Roma, Italy, 4-6 July 2012.

34. Zambon, G.; Benocci, R.; Brambilla, G. Cluster categorization of urban roads to optimize their noise Monitoring. Environ. Monit. Assess. 2016, 188. [CrossRef] [PubMed]

35. Barrigón Morillas, J.M.; Gomez, V.; Mendez, J.; Vilchez, R.; Trujillo, J. A categorization method applied to the study of urban road traffic noise. J. Acoust. Soc. Am. 2005, 117, 2844-2852. [CrossRef]

36. Smiraglia, M.; Benocci, R.; Zambon, G.; Roman, H.E. Predicting Hourly Traffic Noise from Traffic Flow Rate Model: Underlying Concepts for the DYNAMAP Project. Noise Mapp. 2016, 3, 130-139. 
37. Zambon, G.; Benocci, R.; Angelini, F.; Brambilla, G.; Gallo, V. Statistics-based functional classification of roads in the urban area of Milan. In Proceedings of the 7th Forum Acusticum, Krakow, Poland, 7-12 September 2014.

38. Zambon, G.; Benocci, R.; Bisceglie, A. Development of optimized algorithms for the classification of networks of road stretches into homogeneous clusters in urban areas. In Proceedings of the 22nd ICSV, Florence, Italy, 12-16 July 2015.

39. Zambon, G.; Benocci, R.; Brambilla, G. Statistical Road Classification Applied to Stratified Spatial Sampling of Road Traffic Noise in Urban Areas. Int. J. Environ. Res. 2016, 10, 411-420.

40. Zambon, G.; Benocci, R.; Bisceglie, A.; Roman, H.E. Milan dynamic noise mapping from few monitoring stations: Statistical analysis on road network. In Proceedings of the 45th INTERNOISE, Hamburg, Germany, 21-24 August 2016.

41. Savage, R. Probability Inequalities of the Tchebycheff Type; Mathematics and Mathematical Physics; National Bureau of Standards: Gaithersburg, MD, USA, 1961; Volume 65B, p. 3.

42. Kaufman, L.; Rousseeuw, P. Finding Groups in Data; Wiley Series in Probability and Mathematical Statistics; Wiley: Hoboken, NJ, USA, 1990.

43. Good Practice Guide for Strategic Noise Mapping and the Production of Associated Data on Noise Exposure. 13 January 2006. Available online: http:/ / sicaweb.cedex.es/docs/documentacion/Good-Practice-Guidefor-Strategic-Noise-Mapping.pdf (accessed on 16 January 2006).

44. Orga, F.; Socoró, J.C.; Alías, F.; Alsina-Pagès, R.M.; Zambon, G.; Benocci, R.; Bisceglie, A. Anomalous noise events considerations for the computation of road traffic noise levels: The DYNAMAP's Milan case study. In Proceedings of the 24th International Congress on Sound and Vibration, London, UK, 23-27 July 2017.

45. Zambon, G.; Benocci, R.; Orga, F.; Alsina-Pagès, R.M.; Alías, F.; Socoró, J.C. Real-time urban traffic noise maps: The influence of anomalous noise events in Milan pilot area of Dynamap. In Proceedings of the 46th INTERNOISE, Hong Kong, China, 27-30 August 2017.

(C) 2018 by the authors. Licensee MDPI, Basel, Switzerland. This article is an open access article distributed under the terms and conditions of the Creative Commons Attribution (CC BY) license (http://creativecommons.org/licenses/by/4.0/). 